\title{
Consumer interpretation of ramipril and clopidogrel medication risk information - implications for risk communication strategies
}

This article was published in the following Dove Press journal:

Patient Preference and Adherence

9 July 2015

Number of times this article has been viewed

\author{
Vivien Tong' \\ David K Raynor ${ }^{2}$ \\ Susan J Blalock ${ }^{3}$ \\ Parisa Aslani' \\ 'Faculty of Pharmacy, The University \\ of Sydney, Sydney, Australia; ${ }^{2}$ School \\ of Healthcare, University of Leeds, \\ Leeds, England, UK; ${ }^{3}$ Eshelman School \\ of Pharmacy, University of North \\ Carolina at Chapel Hill, Chapel Hill, \\ NC, USA
}

Purpose: Side effects and side-effect risk information can be provided using written medicine information. However, challenges exist in effectively communicating this information to consumers. This study aimed to explore broad consumer profiles relevant to ramipril and clopidogrel side-effect risk information interpretation.

Methods: Three focus groups were conducted ( $\mathrm{n}=18$ consumers) exploring consumer perspectives, understanding and treatment decision making in response to ramipril and clopidogrel written medicine information leaflets containing side effects and side-effect risk information. All discussions were audio recorded, transcribed verbatim, and analyzed to explore consumer profiles pertaining to side-effect risk appraisal.

Results: Three consumer profiles emerged: glass half-empty, glass half-full, and middle-of-theroad consumers, highlighting the influence of perceived individual susceptibility, interpretation of side-effect risk information, and interindividual differences, on consumers' understanding of side-effect risk information. All profiles emphasized the importance of gaining an understanding of individual side-effect risk when taking medicines.

Conclusion: Written side-effect risk information is not interpreted uniformly by consumers. Consumers formulated their own construct of individual susceptibility to side effects. Health care professionals should consider how consumers interpret side-effect risk information and its impact on medication use. Existing risk communication strategies should be evaluated in light of these profiles to determine their effectiveness in conveying information.

Keywords: adverse effects, risk assessment, drug labeling, consumer participation, comprehension

\section{Introduction}

Consumers desire information regarding the risk of medication side effects. ${ }^{1,2}$ The complexity of communicating this type of information to consumers is apparent from both medicine information development and consumer perspectives. The process relies on obtaining relevant and accurate risk data and effectively communicating these data to consumers to facilitate understanding of the risks associated with their medicines. Different approaches to communicating side-effect risk information can also influence consumer interpretation of risk and views about a medicine, ${ }^{3}$ potentially impacting medication use and patient safety.

Written medicine information (WMI), in the form of patient information leaflets, is an important information source for consumers and a useful avenue through which side-effect risk information can be conveyed. Different side-effect risk communication strategies for WMI have encompassed various recommendations over time. These include verbal descriptors (such as "common" or "rare") advocated for use by the
Faculty of Pharmacy, Pharmacy and Bank Building (AI5), The University of Sydney, Sydney, NSW 2006, Australia

Tel +6I 290367270

Fax +6| 2 935| 439|

Email vivien.tong@sydney.edu.au 
European Commission, ${ }^{4}$ which have been shown to lead to consumer misunderstanding of medication risks, ${ }^{5,6}$ and the updated UK guidelines that provide detailed recommendations, such as only using verbal descriptors together with relevant numerical risk information (such as "common" may affect up to one in ten people), and strategies to help minimize consumer misinterpretation when communicating side-effect risk information. ${ }^{7}$

In Australia, WMI (known as Consumer Medicine Information [CMI]) leaflets must be legally available for all prescription medicines and a proportion of nonprescription medicines (nonprescription medicines that must be handed out by the pharmacist). ${ }^{8}$ As part of the legislation outlining the requirements for CMI content, side-effect information must be included along with any necessary actions to take if side effects occur. ${ }^{9}$ However, similar to other international regulatory contexts, there is no legal requirement for numerical side-effect risk information to be included in WMI, which may present a potential for a mismatch between consumer information needs and WMI content. ${ }^{10}$ This lack of information communicated to consumers may also impact their medication side-effect risk appraisal processes.

Previous work has demonstrated inconsistency in consumers' understanding of terms used to communicate sideeffect information in WMI. ${ }^{11}$ Numerical side-effect risk information presentation (percentages or natural frequencies) and framing (positive or negative) had some influence on consumer risk appraisal processes. ${ }^{11}$ Despite consumers being the target population for which WMI is developed, there has been limited work to date that specifically examines interpersonal variation in the interpretation of side-effect risk information included in WMI. In this paper, we examine this type of variability in an Australian context and identify different consumer profiles that may help explain this variability.

\section{Material and methods}

This paper analyzes data collected as part of a previous study ${ }^{11}$ that investigated consumer opinions on side-effect information presentation in both existing Australian CMI leaflets and researcher-developed WMI for ramipril and clopidogrel and explored their understanding of the likelihood and severity of potential side effects. As part of the study, CMI leaflets for ramipril and clopidogrel were revised ${ }^{11}$ with the support of good information design, functional linguistics, and medicine information expertise. ${ }^{10}$ In particular, relevant psychological theories (fuzzy trace theory, ${ }^{12,13}$ affect heuristic, ${ }^{14-16}$ frequency hypothesis, ${ }^{12}$ and cognitive-experiential ${ }^{17}$ ) were applied to support the written communication of side-effect risk information in the revised WMI. Four alternative WMI leaflet versions were developed, with changes made to the side effects' section (a detailed outline of the development process has been published previously). ${ }^{11}$ Version 1 did not include any numerical side-effect risk information; however, the side effects were presented using tables. Version 2 included positively framed numerical side-effect risk information (likelihood of not experiencing the side effect[s]), communicated using percentages, and benefit information of taking the medicine. Version 3 was the same as Version 2 minus the benefit information. Version 4 included negatively framed numerical side-effect risk information (likelihood of experiencing the side effect[s]), communicated using natural frequencies.

Three focus groups (Sydney, Australia) were conducted with 18 consumers in total as part of the qualitative exploration to address the research aims. ${ }^{11}$ Thematic or data saturation was achieved, ${ }^{18}$ as discussed and agreed upon by members of the research team in relation to the study objectives, and no further focus groups were conducted. Recruitment was conducted by a market research company using a recruitment brief provided by the researchers. Participants were eligible to participate in the study if they were:

- $\geq 50$ years

- Taking one prescription medicine or more, or had done so in the 6 months prior to participation in the study

- Conversant in English

- Not taking ramipril or clopidogrel at the time of the study.

The existing Australian CMI leaflets were provided to consumers in advance of the focus groups, and redeveloped WMI leaflets were provided as stimulus material to consumers during the focus groups for discussion about their perspectives, interpretation of information, and impact on treatment decision making and intention to take the medication, in light of the available WMI leaflets, using a semistructured focus group protocol developed by the researchers. Consumers' interpretation of side-effect risks was explored in more detail. The focus of this paper is on the interpersonal differences, consumer risk appraisal patterns, and their implications for WMI development.

All focus group discussions were audio recorded, with consent obtained from the participants, and transcribed verbatim. The data were analyzed to explore consumer profiles specifically in the context of side-effect risk information interpretation. Verification of all transcripts was completed against the corresponding audio recording for accuracy prior to data analysis. Data analysis was conducted independently 
by two researchers (PA and VT) for validity purposes, and the content was thematically analyzed. ${ }^{19}$ Each researcher analyzed the transcripts independently by hand, where subthemes relating to variability in side-effect risk information interpretation were identified inductively. The findings of the independent data analysis were then discussed, consolidated, and agreed upon within the research team. This synthesis formed the basis of the identification of the broad consumer profiles presented in this paper. Ethics approval for the study was granted by the University of Sydney Human Research Ethics Committee.

\section{Results}

A total of nine females and nine males participated in the study, aged between 50 years and 65 years (mean 58 years). The majority were born in Australia, with English the predominant language spoken at home. The highest level of education completed by most participants was reported as the Higher School Certificate (year 12) or below (such as the School Certificate [year 10] or primary school [year 6]).

There was considerable variability among focus group participants in how they interpreted the side-effect risk information provided in the leaflets. Three primary profiles emerged from the data: 1) glass half-empty consumers, 2) glass half-full consumers, and 3) middle-of-the-road consumers. The characteristics associated with each profile are described below together with illustrative quotes and are summarized in Table 1.

\section{Glass half-empty consumers}

Glass half-empty consumers perceived themselves to be at an increased risk of experiencing medication side effects or displayed apprehension toward specific side-effect risks which impacted their stated likelihood of using the medication if, for instance, their doctor prescribed it for them.
As I was reading this, that's the first thing I thought. If my doctor says "I'm going to put you on this", I [would] go "no, you're not" because I've read the pamphlet [existing Australian CMI without numerical information] mate and I don't think it's a good risk, because there is too much. There is too much that can happen. [focus group 2 (FG2); male 1 (M1)].

I think that's overwhelming. I'd look at that and think

"I'm not taking that". [FG3; female 1 (F1)].

Past experience of side effects led to heightened perceived individual risk of experiencing side effects, where wariness was evident in light of previous side effects experienced by, for example, a family member. Consumer perceptions of their own individual risk in many respects overruled the numerical risk information and/or how the information was framed.

Yeah [I would] most probably get them. [My daughter] would get them. [FG2F1].

The magnitude of risk made little difference to glass halfempty consumers. For example, even side effects classified as "very rare" and having a likelihood of $<1$ in 10,000 were still large enough for a glass half-empty consumer to say they would be dissuaded from taking the study medicine.

\section{Glass half-full consumers}

Glass half-full consumers were largely confident that they would not experience side effects or had a more favorable view of the benefit-risk profile of the medicine. Decreased perceived individual risk played a role in leading this positive outlook.

I'm optimistic and I don't count myself as the one in the hundred [who experience the side effect]. [FG3F2].

Consumers utilized and interpreted positively framed side-effect information (eg, likelihood of not experiencing

Table I Summary of the core characteristics of the identified consumer profiles

\begin{tabular}{ll}
\hline Profile & Description of core characteristics \\
\hline Glass half-empty consumers & $\begin{array}{l}\text { Considers themselves as part of the group who will experience the medication side effect(s) } \\
\text { Perceived medication risks outweigh the potential benefits, which then affect projected } \\
\text { intention to take the medication } \\
\text { Heightened perceived individual risk takes precedence }\end{array}$ \\
Glass half-full consumers & $\begin{array}{l}\text { Generally confident that they would not experience the medication side effect(s) } \\
\text { Perceived individual risk lower }\end{array}$ \\
Perceived favorable benefit-risk profile for the medicine \\
Cannot ascertain their own likelihood of experiencing side effect(s) after reading the \\
information \\
$\begin{array}{l}\text { Focused primarily on individual risk rather than the numerical information presented } \\
\text { Trust in the prescribing doctor overrides the need to determine the risk of experiencing } \\
\text { medication side effect(s) }\end{array}$
\end{tabular}


the side effect is 99\%) and benefit information included in WMI (when noticed) together with risk information to help establish their own perceived benefit-risk profile for the medicine.

What you're saying here is these are the side effects that could happen and you could get all of them or none of them and at the end of the day it's going to do more good than it's going to do harm. You'd definitely take them. [FG1M3].

\section{Middle-of-the-road consumers}

Middle-of-the-road consumers were unable to ascertain the likelihood of experiencing a side effect after reading information about the medication. For instance, when asked what the numerical side-effect risk information meant, one participant said: Nothing, it means nothing to me. [FG1F2].

A large contributor to this was consumers' focus on determining their own individual risk.

I think generally, if you do feel that and you know your body reasonably well then, if it's serious you'll feel something and you know if it's happened since you've been taking this. My best thing is my body telling me that this is not working for me. [FG1F2].

Despite reading the information, some consumers disregarded numerical side-effect risk information because they believed that true likelihood was not being conveyed, that numerical information did not equate to the necessary action required to be taken if a side effect was experienced, or because they could not interpret and apply the numerical information.

If I experience anything I'm not going to worry about what number out of a hundred. I'm going to go to my doctor to work it out. I don't want to be worried about percentages or anything. [FG1F2].

Some felt that the presented numerical side-effect risk information could not be completely trusted:

No. Not even the doctor knows himself. [FG2F2].

They are just a guide. [FG2M1].

Consumers also discussed the notion of trust in the doctor prescribing the medication, where, for example, it negated the need to ascertain the risk of experiencing side effects.

As far as I'm concerned, if I need to take that then that's what I need to take because the doctor said I should take it. It doesn't matter if there's a chance of it killing me or a chance of it making me ill. [FG3M2].

\section{Discussion}

Overall, three profiles were identified based on how consumers understood and interpreted side-effect information. These profiles represented a spectrum of consumer perceptions about their likelihood of experiencing side effects. Individual risk was the core focus for many consumers. When making decisions about medication use, consumers relied heavily on perceptions of individual susceptibility and were influenced by their own traits, experience, and how side-effect information was understood. Moreover, some wanted more information about the test population from which the numerical risk data were determined such as its sample size, as previously reported with this group of participants. ${ }^{11}$ This could then possibly allow consumers to better relate this information to their own risk and to ascertain the relevance of these data to their personal susceptibility of experiencing medication side effects. This is in line with social comparison theory, which posits that people often assess themselves via comparison with similar others. ${ }^{20}$ The lack of this information in the WMI leaflets may account for why some participants had difficulty in interpreting the numerical risk information.

Several factors were found to underpin the application of side-effect risk information to the consumer's own situation. These included an accurate understanding and interpretation of the information, an understanding of general risk information, susceptibility to positive framing effects (similarly identified in previous work), ${ }^{21}$ and personal characteristics and skills. These factors highlight the role of a learned intermediary in assisting to interpret and personalize sideeffect information. Another future consideration would be the potential for tailored WMI; ${ }^{22}$ however, the feasibility of such a strategy requires further exploration. With the absence of a single effective approach to adopt when communicating side-effect risk information in WMI, which would facilitate appropriate risk understanding for all consumers, learned intermediaries such as pharmacists and doctors remain the key link in tailoring information for each consumer, particularly when taking into account overarching differences in health literacy and/or numeracy levels between consumers across all profiles. Spoken information provided to complement WMI could help all consumers, in particular middleof-the-road consumers, to better understand the treatment rationale and potential benefits and risks associated with medication use. Consequently, as with WMI, attention should be paid to how spoken information is expressed or framed to help better facilitate informed treatment decision making.

Limitations exist in the side-effect risk data available and transparency of numerical reporting to consumers via WMI. Thus, varied approaches adopted by medicine information 
developers when communicating side-effect risk may have varying impacts on the broad consumer profiles identified and the interpretation of information by consumers. For glass half-empty consumers, the inclusion of useful benefit information in WMI may allow for more balanced understanding of treatment expectations, when conveyed alongside numerical side-effect risk information, clear indications of side-effect severity, and actions required to be taken if side effects are experienced. Hamrosi et al also found that consumers generally viewed broad benefit information in WMI favorably, where it acted as a motivator for medication use. ${ }^{23}$ However, more importantly, benefit information should be responsibly communicated alongside side-effect risk information to help ensure that treatment benefits are not amplified by glass half-full consumers. Additionally, further exploration is needed in order to work in partnership with middle-of-the-road consumers to find better strategies to convey available side-effect risk information in a more meaningful way. There is also the possibility that these individual differences in medication risk information interpretation may not be stable across all medications for all medical conditions, particularly in light of other factors such as self-perceived health status. Therefore, these three profiles are not necessarily mutually exclusive for a single given patient at different time points across different medicines being used.

The three consumer profiles illustrate identified patterns in consumers' approach, perceived relevance, and appraisal of communicated written side-effect risk information. Together with the previously published findings ${ }^{11}$ from this study (consumer perspectives of the WMI leaflets and the impact of how side-effect risk information was communicated on consumer understanding of this information), communicators of risk information (whether verbal or written) may find these findings useful to consider in an attempt to minimize a potential disconnect between the intended versus actual usefulness of side-effect risk information to consumers. However, there are study limitations that should be acknowledged. The choice of exemplar study medicines ramipril and clopidogrel may have introduced a medicine bias and potentially affected consumers' interpretation of the information, and thus, the profiles identified. It may also have been useful to explore the usability of the WMI leaflets initially, prior to their use as stimulus material in the focus groups, to help map these focus group findings against leaflet usability data. This is critical as the next step if the inclusion of similar side-effect risk information in WMI leaflets such as CMI is to be implemented. ${ }^{24}$ As these identified consumer profiles may not be exhaustive, further quantitative profiling of larger consumer populations is required to better discern consumer characteristics confounded by different medical conditions and medications, alongside other demographic factors which may not be represented in this study cohort. Such work will be necessary to inform and refine best practice approaches to side-effect risk communication in WMI within an international context for consumers of both prescription and nonprescription medicines.

\section{Conclusion}

Three consumer profiles were identified that illustrate how consumers appraise medication side-effect risk information. Consumers placed specific emphasis on formulating their own construct of individual susceptibility to side effects when reading side-effect information. Consumers' interaction with WMI does not lead to a singular way in which medicine risks are perceived and interpreted, highlighting the need for medicine information writers and/or health care professionals to consider furthering the discussion surrounding a more tailored approach to providing side-effect information to consumers. Any WMI strategies arising from this will require further performance testing to be conducted to ensure WMI usability. WMI does not replace spoken information, and health care professionals have a key role in assisting with the interpretation of side-effect information for individuals in their care.

\section{Acknowledgments}

The authors wish to thank all the focus group participants for their valuable time and input.

\section{Disclosure}

David K Raynor is the cofounder and academic advisor for Luto Research Ltd, a company that provides performancebased testing services for health information. The authors report no other conflicts of interest in this work.

\section{References}

1. Raynor DK, Blenkinsopp A, Knapp P, et al. A systematic review of quantitative and qualitative research on the role and effectiveness of written information available to patients about individual medicines. Health Technol Assess. 2007;11(5):iii, 1-160.

2. Raynor DK, Savage I, Knapp P, Henley J. We are the experts: people with asthma talk about their medicine information needs. Patient Educ Couns. 2004;53(2):167-174.

3. Knapp P, Raynor DK, Berry DC. Comparison of two methods of presenting risk information to patients about the side effects of medicines. Qual Saf Health Care. 2004;13(3):176-180.

4. European Commission. A Guideline on the Readability of the Label and Package Leaflet of Medicinal Products for Human Use. Brussels: European Commission Pharmaceutical Committee; 1998 [cited October 26, 2014]. Available from: http://pharma.be/assets/files/854/854_12890 1376878944246.pdf. Accessed October 26, 2014. 
5. Berry D, Raynor T, Knapp P, Bersellini E. Over the counter medicines and the need for immediate action: a further evaluation of European Commission recommended wordings for communicating risk. Patient Educ Couns. 2004;53(2):129-134.

6. Berry DC, Raynor DK, Knapp P. Communicating risk of medication side effects: an empirical evaluation of EU recommended terminology. Psychol Health Med. 2003;8(3):251-263.

7. Medicines and Healthcare Products Regulatory Agency. Guideline on Communication of Risks and Benefits in Patient Information Leaflets; 2005 [cited October 26, 2014]. Available from: http://www.mhra.gov. uk/home/groups/pl-a/documents/websiteresources/con049315.pdf. Accessed October 26, 2014.

8. Aslani P. Consumer medicine information conundrums. Aust Prescr. 2007;30(5):122-124.

9. Therapeutic Goods Regulation 1990, Australia [Regulation on the Internet]; 2014 [cited May 4, 2015]. Available from: http://www.comlaw.gov. au/Details/F2014C00898. Accessed May 4, 2015.

10. Aslani P, Hamrosi K, Feletto E, et al. Investigating Consumer Medicine Information (I-CMI) Project. Sydney: The Pharmacy Guild of Australia, Australian Government Department of Health and Ageing; 2010.

11. Tong V, Raynor DK, Blalock SJ, Aslani P. Exploring consumer opinions on the presentation of side-effects information in Australian Consumer Medicine Information leaflets. Health Expect. In press 2014.

12. Reyna VF, Nelson WL, Han PK, Dieckmann NF. How numeracy influences risk comprehension and medical decision making. Psychol Bull. 2009;135(6):943-973.

13. Reyna VF. A theory of medical decision making and health: fuzzy trace theory. Med Decis Making. 2008;28(6):850-865.
14. Slovic P, Finucane ML, Peters E, MacGregor DG. Risk as analysis and risk as feelings: some thoughts about affect, reason, risk, and rationality. Risk Anal. 2004;24(2):311-322.

15. Slovic P, Peters E. Risk perception and affect. Curr Dir Psychol Sci. 2006;15(6):322-325.

16. Slovic P, Peters E, Finucane ML, MacGregor DG. Affect, risk, and decision making. Health Psychol. 2005;24(suppl 4):S35-S40.

17. Reyna VF, Brainerd CJ. Numeracy, ratio bias, and denominator neglect in judgments of risk and probability. Learn Individ Differ. 2008; 18(1):89-107.

18. Krueger RA, Casey MA. Focus Groups: A Practical Guide for Applied Research. Thousand Oaks: Sage Publications; 2009.

19. Green J, Thorogood N. Qualitative Methods for Health Research. 3rd ed. London: Sage Publications Ltd; 2014.

20. Festinger L. A theory of social comparison processes. Hum Relat. 1954; 7(2):117-140.

21. Taylor J, Seyed-Hosseini M, Quest D. Framing the risk of an OTC medication side effect. Can Pharm J (Ott). 2011;144(1):34-39.

22. Dickinson R, Hamrosi K, Knapp P, et al. Suits you? A qualitative study exploring preferences regarding the tailoring of consumer medicines information. Int J Pharm Pract. 2013;21(4):207-215.

23. Hamrosi K, Dickinson R, Knapp P, et al. It's for your benefit: exploring patients' opinions about the inclusion of textual and numerical benefit information in medicine leaflets. Int J Pharm Pract. 2013;21(4): 216-225.

24. Sless D, Shrensky R. Writing About Medicines for People: Usability Guidelines for Consumer Medicine Information. 3rd ed. North Sydney: Australian Self Medication Industry; 2006.
Patient Preference and Adherence

\section{Publish your work in this journal}

Patient Preference and Adherence is an international, peer-reviewed, open access journal that focuses on the growing importance of patient preference and adherence throughout the therapeutic continuum. Patient satisfaction, acceptability, quality of life, compliance, persistence and their role in developing new therapeutic modalities and compounds to optimize

\section{Dovepress}

clinical outcomes for existing disease states are major areas of interest for the journal. This journal has been accepted for indexing on PubMed Central. The manuscript management system is completely online and includes a very quick and fair peer-review system, which is all easy to use. Visit http://www. dovepress.com/testimonials.php to read real quotes from published authors. 